\title{
TORT3D: A MATLAB code to compute geometric tortuosity from 3D images of unconsolidated porous media
}

\author{
Riyadh I. Al-Raoush ${ }^{\text {a,* }}$, Iman T. Madhoun ${ }^{\text {b }}$ \\ a Department of Civil and Architectural Engineering, Qatar University, PO Box 2713, Doha, Qatar \\ b Environmental Engineering Master Program, College of Engineering, Qatar University, PO Box 2713, Doha, Qatar
}

\section{A R T I C L E I N F O}

\section{Article history:}

Received 12 March 2017

Received in revised form 9 June 2017

Accepted 29 June 2017

Available online 13 July 2017

\section{Keywords:}

Tortuosity

Computed tomography

Pore space

Medial surface

Unconsolidated

Porous media

\begin{abstract}
A B S T R A C T
Tortuosity is a parameter that plays a significant role in the characterization of complex porous media systems and it has a significant impact on many engineering and environmental processes and applications. Flow in porous media, diffusion of gases in complex pore structures and membrane flux in water desalination are examples of the application of this important micro-scale parameter. In this paper, an algorithm was developed and implemented as a MATLAB code to compute tortuosity from three-dimensional images. The code reads a segmented image and finds all possible tortuous paths required to compute tortuosity. The code is user-friendly, easy to use and computationally efficient, as it requires a relatively short time to identify all possible connected paths between two boundaries of large images. The main idea of the developed algorithm is that it conducts a guided search for connected paths in the void space of the image utilizing the medial surface of the void space. Once all connected paths are identified in a specific direction, the average of all connected paths in that direction is used to compute tortuosity. Three-dimensional images of sand systems acquired using X-ray computed tomography were used to validate the algorithm. Tortuosity values were computed from three-dimensional images of nine different natural sand systems using the developed algorithm and compared with predicted values by models available in the literature. Findings indicate that the code can successfully compute tortuosity for any unconsolidated porous system irrespective of the shape (i.e., geometry) of particles.
\end{abstract}

(C) 2017 Elsevier B.V. All rights reserved.

\section{Introduction}

Tortuosity is a significant parameter that has a profound impact on flow and transport characteristics of porous media. Tortuosity is defined as the average ratio of the lengths of the actual paths that molecules travel from one point to the final destination through the pore (void) space of a porous medium to the length of the straight path between these points [58]. The importance of tortuosity can be observed in many engineering applications (e.g., diffusion, mass transfer and separation of mixtures) $[10,16,40,42,68]$. In geosciences applications, tortuosity impacts flux of the fluids in the pore space $[28,72,74,89]$. In acoustics applications, tortuosity is a significant parameter that impacts sound propagation and its velocity variations in the pore space $[3,42,90]$. In water applications, membrane tortuosity is a major factor that affects its distillation performance [35].

Tortuosity has a significant impact on single and multiphase flow and transport properties $[7,46,60,62]$. For instance, diffusion and

\footnotetext{
* Corresponding author.

E-mail addresses: riyadh@qu.edu.qa (R.I. Al-Raoush), Imadhoun@qu.edu.qa (I.T. Madhoun).
}

permeability of fluids in a porous medium are directly related to its tortuosity. Diffusion coefficient can be estimated as [27]:

$D_{p}=\frac{\varepsilon D_{b}}{\tau^{2}}$

where $D_{p}$ is the diffusion coefficient in the porous media $\left[\mathrm{L}^{2} \mathrm{~T}^{-1}\right], D_{b}$ is the diffusion coefficient in air or water, $\varepsilon$ is porosity and $\tau$ is tortuosity.

Whereas permeability, $k$, is related to tortuosity, $\tau$, by KozenyCarman equation as [85]:

$k=\frac{\varepsilon^{3}}{\beta \tau^{2} S^{2}}$

where $\varepsilon$ is porosity, $\beta$ is a shape related factor, and $S$ is the average pore perimeter [85].

Moreover, tortuosity of a porous medium influences the magnitude and detailed structure of the entrapped fluids in the pore space $[6,73]$. The distribution and configurations of the entrapped fluids in the void space of subsurface systems is critical to enhanced oil recovery, rate and efficiency of hydrocarbon production, carbon sequestration 
management $[23,51,77,84]$ and the integrity of subsurface storage applications $[15,32,87]$.

Geometric tortuosity, $\tau_{g}$, can be defined as [25]:

$\tau_{g}=\frac{<L_{g}>}{L_{S}}$

where $<L_{g}>$ is the average length of true paths through the porous media and $L_{s}$ is the length of the straight-line across the porous media in the direction of flow. Geometric tortuosity can also be defined as the ratio of the shortest pathway to the straight-line length [1] Based on the definition given in Eq. (3), the value of geometric tortuosity is always greater than one, whereas the coefficient of geometric tortuosity, $\left(\mathrm{Tg}=\frac{1}{\tau_{g}}\right)$, is less than one [25].

Several analytical, experimental, and numerical approaches have been used to determine tortuosity of porous media. Ahmadi et al. [2] proposed analytical expressions of tortuosity and permeability using the concept of representative elementary volume (REV) of cubic array of spheres. Lanfrey et al. [41] and Li and Yu [43] numerically modeled geometric tortuosity as function of porosity for random packs of identical particles of discrete pore size distributions. While such investigations provide useful models to relate tortuosity to the geometry of the porous media, they are limited to ideal systems with known geometry; their application to natural porous media with irregular geometries is questionable (e.g., $[2,41,88,91])$.

Experimentally, tortuosity has been measured indirectly by conducting fluid diffusion experiments ([14,24,78] and electrical conductivity measurements $[12,52]$. While these methods provide a reasonable estimate of tortuosity, the inability to link tortuosity to the geometry and topology of the pore space (i.e., connectivity, pore-body and pore-throat distributions) is considered a major limitation in applying such methods [79].

Other researchers have implemented numerical simulations to determine tortuosity. For instance, Matyka et al. [48] computed tortuosity by simulating flow streamlines by solving the flow equations at low Reynolds number regime. They simulated the porous medium as twodimensional randomly distributed and overlapping squares of equal sizes. Sun et al. [79] applied a numerical simulation to determine tortuosity of two-dimensional homogenous porous media of representative elementary volume (REV) of circular particles and developed a model that relates tortuosity to porosity. Tortuosity was calculated by solving the local boundary-value problem to calculate an effective diffusive coefficient. While such methods provide an alternative to compute tortuosity, they are limited to two-dimensional systems with an ideal geometry.

Recent advances in non-destructive imaging technologies such as computed tomography have been increasingly used in the research community to obtain three-dimensional images of the interior of porous media non-destructively. The need to visualize and understand the complexity of the interior of porous media systems has prompted the development of algorithms for visualization, image processing and data analysis. Extensive research has been conducted to measure tortuosity using two-dimensional and three-dimensional images [54,65,76,80]. A range of image-based algorithms have been developed to measure tortuosity of porous media from images, including medial axis $[11,44,59,80,83]$, Dijkstra algorithm [58,76], random walk simulation [29,65-67], fast marching method, thin-line skeleton $[33,58,70]$ and A-star algorithm $[17,50]$.

The medial axis algorithm has been implemented in commercial software such as 3DMA software $[11,34,57,81]$ and 3DMA-Rock software $[9,54,55]$. A chessboard distance algorithm has been implemented in Avizo software [38]. Both softwares were used to measure tortuosity of porous media from three-dimensional images of soil aggregates [56], sand samples (i.e., Accusand and Granusil) [54] sand sediments acoustic [69] and siliceous mudstones [80]. However, one of the main disadvantages of the medial axis algorithm implemented in 3DMA and 3DMA-
Rock is its sensitivity to small changes in the boundary of the void space which leads to a large change in the generated skeleton [13]. Another disadvantage is the high cost of softwares, which make them prohibitive and not easily accessed by researchers.

Dijkstra's shortest path algorithm [18] has been implemented and used to compute tortuosity from three-dimensional images $[61,75,76]$. However, the search for the shortest paths using the Dijkstra algorithm is computationally expensive even when applied to small images (e.g., Berea image with a size of $450 \times 450 \times 510$ voxels [64]).

In summary, although analytical, experimental and numerical approaches have been developed and used to measure tortuosity of porous media systems, there are some limitations associated with these approaches. For instance, analytical approaches determine tortuosity for ideal systems, where such systems do not represent natural porous media systems. Most imaged-based algorithms are implemented in commercial softwares that are not readily available to researchers as they are very costly. Moreover, diffusion-based experiments typically used for tortuosity measurements, fail to link tortuosity to the geometry and topology of the pore space.

Therefore, given the significance of tortuosity and its impact on many engineering applications coupled with the advances in the use of 3D imaging technologies, there is a need to develop an accurate, efficient and accessible code that can be used to obtain tortuosity of unconsolidated porous media from 3D images. The objective of this paper is to present, TORT3D, a MATLAB code that was developed to compute geometric tortuosity from 3D images. The code not only provides a scalar value of tortuosity, but also provides a three-dimensional description of all connected paths in the image, which in turn links tortuosity to the geometry, and topology of the pore space (i.e., connectivity, pore-body and pore-throat distributions). Such link is critical for threedimensional simulations of flow and transport phenomena in porous media. The code reads segmented (i.e., binary) images and can be applied to 3D images of any unconsolidated porous media systems to identify all possible tortuous paths. TORT3D is available to the scientific community in the Supplementary Material section of the Journal. The paper demonstrates the capability of the code to compute tortuosity from images of different natural sand systems.

The paper is organized as follows: Section 2 presents the main steps of the algorithm, Section 3 provides application of the code to 3D Computed Tomography images of natural sand systems and comparison with existing tortuosity models and Section 4 presents conclusions.

\section{Description of Tort3D code}

The key functionality of Tort3D code is its capability to compute geometric tortuosity from 3D images of porous media using MATLAB environment. The code is user-friendly and easy to use where input parameters and user interaction are minimized. It can be used to compute tortuosity from 2D or 3D images. It has the option to select the direction of tortuosity computations along a given direction (i.e., $\mathrm{x}, \mathrm{y}$, or $\mathrm{z}$ ) and the connectivity of voxels (i.e., number of neighboring voxels/pixels while searching for connected paths). Moreover, it is computationally efficient, as it requires a relatively short time (few minutes) to identify all possible connected paths between two boundaries of large images that are used to compute tortuosity. This is mainly due to the optimized coding scheme used where loops, nested loops, and "if statements" are limited in the code. Input and output variables are given in Table 1.

The general flow chart of the algorithm is given in Figs. 1 and 2. The algorithm commences by reading segmented (i.e., binary) images. Note that the segmentation process is beyond the scope of this paper, many published papers have presented and discussed different segmentation algorithms such as k-means clustering [37,39,45,86], Mean-Shift Clustering $[19,22,53]$, watershed $[26,36,47]$ and Normalized Graph Cuts $[5,31,82]$.

The main idea of the developed algorithm is that it conducts a guided search for connected paths in the void space of the image utilizing the 
Table 1

List of input and output variables of the developed code.

\begin{tabular}{|c|c|}
\hline \multicolumn{2}{|l|}{ Input variables } \\
\hline "Raw_image" & Segmented (binary) image (MAT format) \\
\hline "Direction_flow" & $\begin{array}{l}\text { A variable that dictates direction of tortuosity calculation } \\
\text { (i.e., direction of flow); (" } 1 \text { " is set for flow in the x direction, " } 2 \text { " for } \\
\text { flow in y direction, " } 3 \text { " for the flow in } \mathrm{z} \text { direction) }\end{array}$ \\
\hline "Connect" & Connectivity type (2D image: 4 or 8 ; 3D image 6,18 or 26 ) \\
\hline \multicolumn{2}{|l|}{ Output variables } \\
\hline "Path_ID" & $\begin{array}{l}\text { All connected paths in the void space between two boundaries } \\
\text { of the input image in direction of flow }\end{array}$ \\
\hline “Starting_Paths” & $\begin{array}{l}\text { Two-dimensional image that shows locations of points used to start } \\
\text { the search of potential connected paths between two boundaries of } \\
\text { the input image in direction of flow path (e.g., Fig. 3) }\end{array}$ \\
\hline “3D_paths” & $\begin{array}{l}\text { Three-dimensional image that displays all connected paths in } \\
\text { the void space between two boundaries of the input image in } \\
\text { direction of flow (e.g., Fig. 8) }\end{array}$ \\
\hline “Tortuosity" & Average geometric tortuosity of the image computed using Eq. (4) \\
\hline
\end{tabular}

medial surface of the void space. The medial surface is a threedimensional surface that simplifies the void space and is constructed by stacking the two-dimensional medial axis of each slice. The advantage of this approach is that it limits the search along the medial surface, which in turn minimizes CPU time and memory requirements to find possible paths in the image. Once all connected paths are identified for a specific direction, the average of all connected paths in that direction is used to compute tortuosity. A connected path is defined as the one that starts from the first slice of the image and ends at the final slice of the image in the direction computation (i.e., connects image boundaries in the direction of flow). Tortuosity is then computed as:

$\tau=\frac{\frac{\sum_{i=1}^{n} l_{p_{i}}}{n}}{l_{s}}$

where $l_{p}$ is a given path through the void space that connects the boundary of the images in the direction of flow, $l_{s}$ is the corresponding straight line (i.e., size of the image in the direction of flow) and $n$ is the number of paths. A brief description of the main elements of the code is described in the subsections below.

\subsection{Generation of the medial surface of the void space}

Three-dimensional medial surface of the void space is generated from two-dimensional skeletonization of the void space of each slice in the image. The medial surface guides the search for connected paths in the void space starting from predefined locations in the first slice in the direction of flow (more details are provided in the next section).

The medial surface provides an efficient representation of the void space by reducing its dimensionality while reserving its topology and geometry [71]. The MATLAB command "bwmorph (BW, 'skel', Inf)" is implemented to obtain the two-dimensional skeletonization for each slice. A controlled erosion is performed and repeated until the thickness of the skeleton of the void space becomes one voxel (i.e., no change is observed in the skeleton).

\subsection{Initiating starting points (pixels) for the search for connected paths}

While each pixel in the void space in the first slice in the direction of flow is a potential starting point for the search of connected paths, only those pixels that form junctions at the medial axis lead to nonredundant paths. These junctions form pore-bodies in the void space and represent centers of inscribed circles (shown as green circles in Fig. 3). To implement a computationally efficient algorithm, the search for connected paths is limited to those locations (i.e., centers of

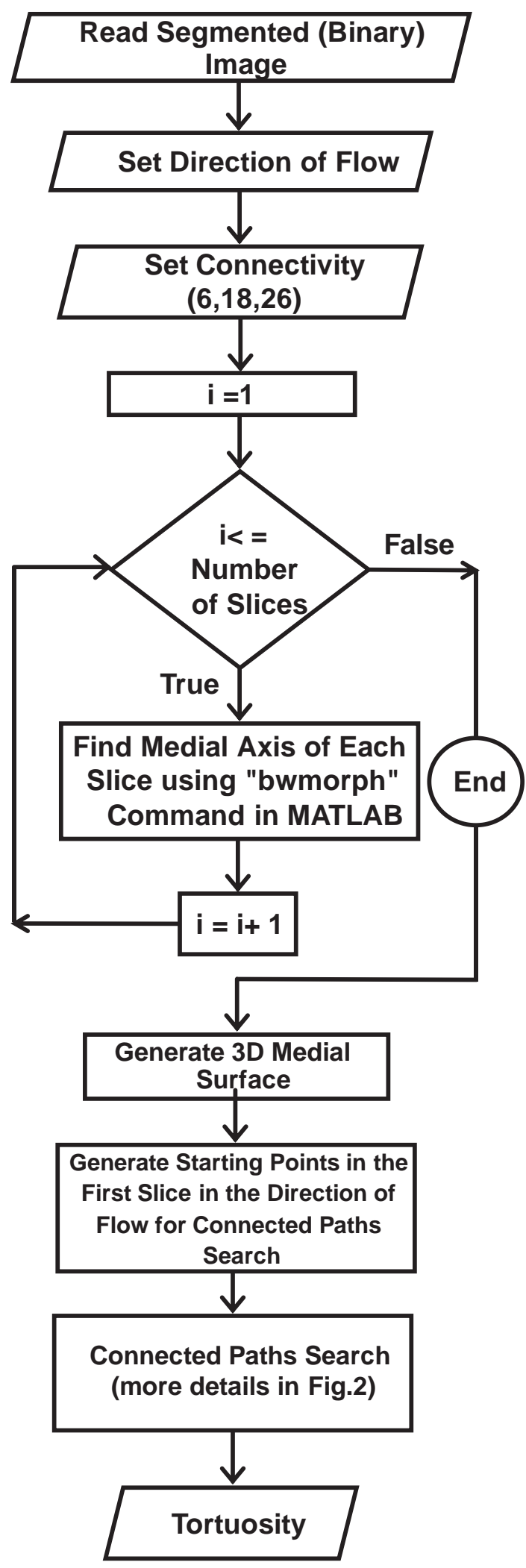

Fig. 1. A flow chart of the developed algorithm to compute tortuosity from 3D images (Search for Connected Paths algorithm is explained in detail in Fig. 2)

pore-bodies in the void space). Therefore, the main goal of this step in the algorithm is to find pixels in the first slice in the direction of flow (i.e., tortuosity computation) that serve as starting points for the search for connected paths. 


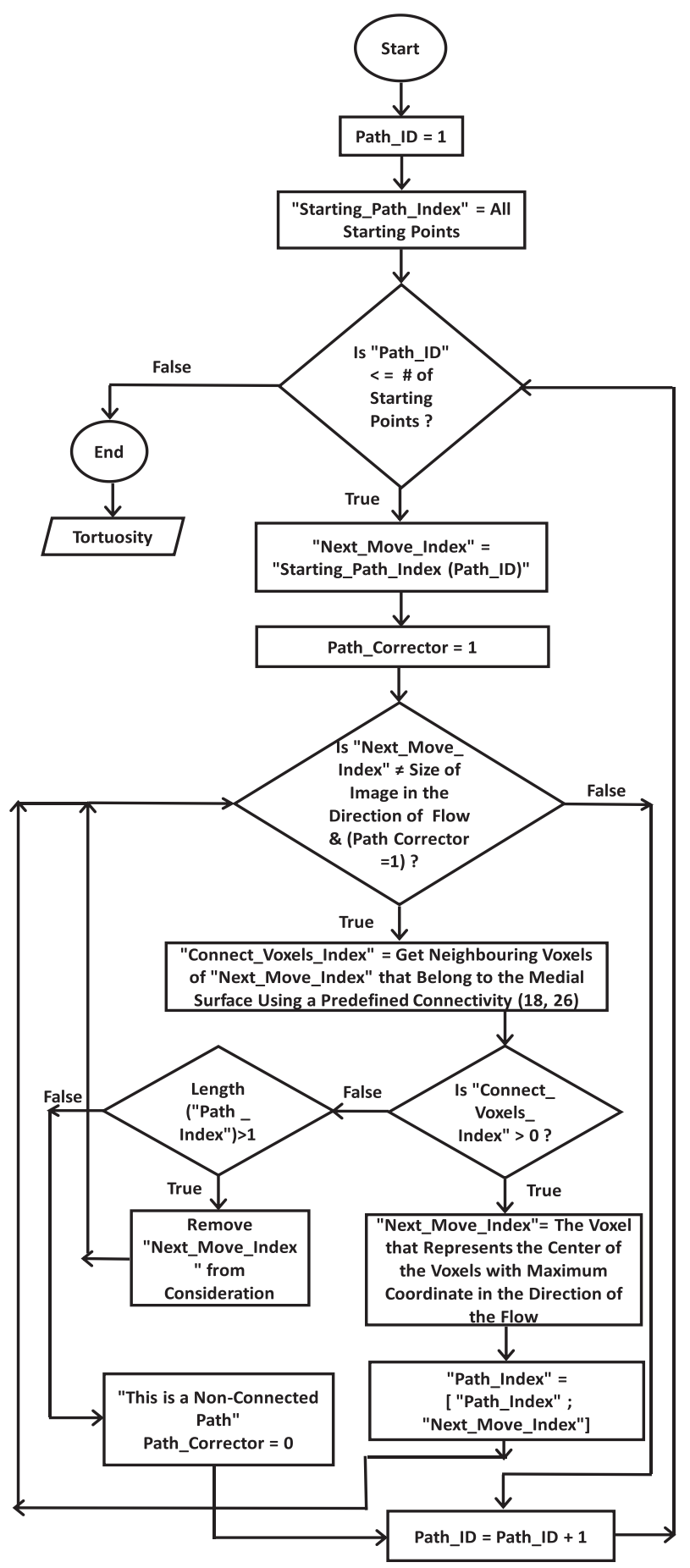

Fig. 2. A flow chart of "Search for Connected Paths" algorithm shown as a step in the algorithm shown in Fig. 1.

\subsection{Search for connected paths}

Identifying connected paths along the three-dimensional medial surface depends on the connectivity of voxels (volume element in 3D images). The algorithm defines the connectivity of a given voxel (or pixel in 2D images) by identifying its neighboring voxels that connect through a face, edge or corner. In 2D images, there are 4 or 8 neighboring pixels for a given pixel, whereas there are 6,18 or 26 neighboring voxels for a given $3 \mathrm{D}$ voxel. In the developed algorithm, the connectivity is defined before the search for connected paths starts. The main elements of the algorithm of finding connected paths are given in the

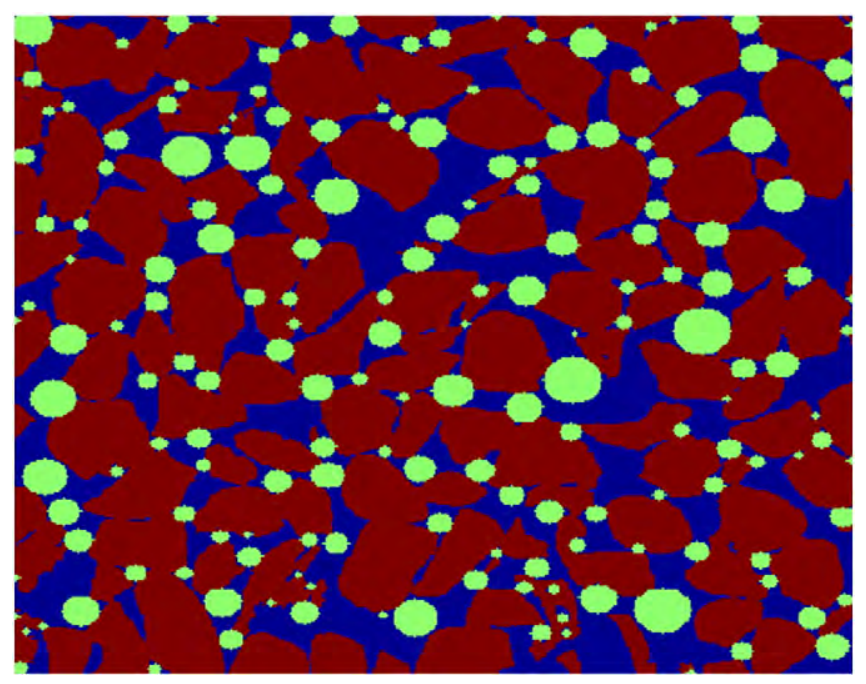

Fig. 3. Starting points of the Search for Connected Paths algorithm (centers of green circles). Red color depicts sand particles and dark blue color represents the void space.

flow chart shown in Fig. 2. The search for connected paths starts from the voxels saved in "Starting_Path_Index" variable that includes all possible starting points in the first slice of the direction of flow. Neighboring voxels of the selected voxel are determined and only voxels that belong to the medial surface are considered as potential voxels in the connected path. The voxel that represents the centroid of the voxels with maximum coordinate in the direction of flow is considered as a voxel in the connected path (i.e., "Next_Move_Index"). However, if the voxel (Next_Move_Index) belongs to a solid phase, it will be removed from consideration and the previous voxel is considered. Then, the algorithm identifies new neighboring voxels and repeats the search on the medial surface as shown in Fig. 2. The search continues until a connected path is found (i.e., path that connects two opposite faces of the image). The above procedure is repeated for all starting voxels saved in "Starting_Path_Index" variable.

\section{Computation of tortuosity using the developed code}

\subsection{Three-dimensional images using X-ray computed tomography}

In order to verify tortuosity computations of the developed code, 3D $\mathrm{X}$-ray computed tomography images of different sand systems were used and tortuosity values were compared to values obtained from numerical and analytical models available in the literature. X-ray computed tomography is a powerful technique used to visualize the internal structure of porous media nondestructively. A three-dimensional image of an object is obtained by converting X-ray attenuation data to a series of cross-sections using image reconstruction algorithms while the sample is rotated by a specific angle. During sample rotation, the X-ray source produces an X-ray beam that passes through a section of the sample where detectors convert the X-ray to tomographs to create an image. During one complete rotation, tomographs are collected and converted to cross-sectional images (slices) of the sample (tomographic reconstruction). Three-dimensional images are then generated from a series of 2D images obtained while the sample is rotated around an axis of rotation.

In this work, 3D images of sand systems were acquired using X-ray computed tomography at the GeoSoilEnviroCARS beamline (13-BM-D) at the Advanced Photon Source, Argonne National Laboratory, USA. Image reconstruction algorithms developed by GeoSoilEnviroCARS were used to convert X-ray attenuation data to cross-sections and then to 3D images. More details can be found in [4]. 
Table 2

Physical properties of the porous media used to obtain 3D images.

\begin{tabular}{|c|c|c|c|c|c|c|c|c|c|c|}
\hline Sand & Porous media & Image size (voxels) & $\varepsilon$ & $d_{50}(\mathrm{~mm})$ & $C_{u}$ & $C_{c}$ & $S_{i}$ & $R_{i}$ & $S A\left(\mathrm{~mm}^{2}\right)$ & $S S A\left(\mathrm{~mm}^{-1}\right)$ \\
\hline \multirow[t]{5}{*}{ Silica } & S1 & $380 \times 380 \times 520$ & 0.37 & 0.35 & 1.85 & 1.12 & 0.90 & 0.83 & 248.33 & 19.46 \\
\hline & $\mathrm{S} 2$ & $380 \times 380 \times 520$ & 0.33 & 0.27 & 1.79 & 1.06 & 0.89 & 0.81 & 316.41 & 23.55 \\
\hline & S3 & $380 \times 380 \times 520$ & 0.35 & 0.27 & 1.79 & 1.07 & 0.89 & 0.81 & 340.35 & 26.18 \\
\hline & S4 & $380 \times 380 \times 520$ & 0.32 & 0.26 & 1.83 & 1.00 & 0.89 & 0.82 & 315.08 & 22.68 \\
\hline & S5 & $380 \times 380 \times 520$ & 0.38 & 0.20 & 1.52 & 1.09 & 0.88 & 0.81 & 450.68 & 36.00 \\
\hline \multirow[t]{4}{*}{ Mixed } & M1 & $380 \times 380 \times 520$ & 0.40 & 0.30 & 2.46 & 1.06 & 0.84 & 0.76 & 274.31 & 22.83 \\
\hline & M2 & $380 \times 380 \times 520$ & 0.40 & 0.25 & 1.96 & 1.09 & 0.85 & 0.77 & 341.00 & 28.68 \\
\hline & M3 & $380 \times 380 \times 520$ & 0.39 & 0.23 & 1.89 & 1.03 & 0.86 & 0.77 & 345.07 & 28.47 \\
\hline & M4 & $380 \times 380 \times 520$ & 0.43 & 0.19 & 1.59 & 1.06 & 0.85 & 0.77 & 434.91 & 39.25 \\
\hline
\end{tabular}

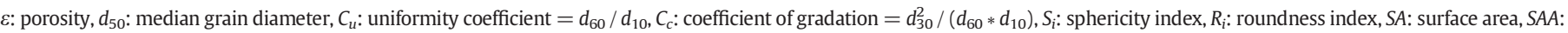
specific surface area $=$ surface area/volume.

\subsection{Natural porous media systems}

Three-dimensional images of nine different sand systems were acquired using computed tomography and used to verify tortuosity values obtained using the developed algorithm. Five sand systems (silica) that represent rounded particles and four systems (mixture of equal masses of silica and quartz sands) that represent irregular particles were used. Physical properties of the systems and sizes of images are given in Table 2. All characteristics given in the table were obtained from 3D images using image-processing algorithms. More details about sample preparations, characterization and tomography imaging can be found in [4]. Samples were selected to provide a tool for code verification by measuring geometric tortuosity of different porous media systems with a range of porosity, median grain diameter and shape indices. Porosity of the silica sand systems (i.e., S1, S2, S3, S4 and S5) ranges between 0.32 and 0.38 . Whereas porosity for the mixed samples (M1, M2, M3 and M4) ranges between 0.39 and 0.43 . Porosity values of mixed sands are higher than values obtained in the silica sand due to difficulty of obtaining dense compactions in systems composed of non-spherical grains. Roundness values of silica sands indicate that the systems are composed of highly rounded grains compared to the mixed sands.

Fig. 4 shows selected cross-sections of silica and mixed sands from 3D tomography images. Two phases are identified in both images, grains (dark red) and void (dark blue). Image resolution is $9.6 \mu \mathrm{m} /$ pixel in all directions and the size of all images used for analysis is $380 \times 380 \times$
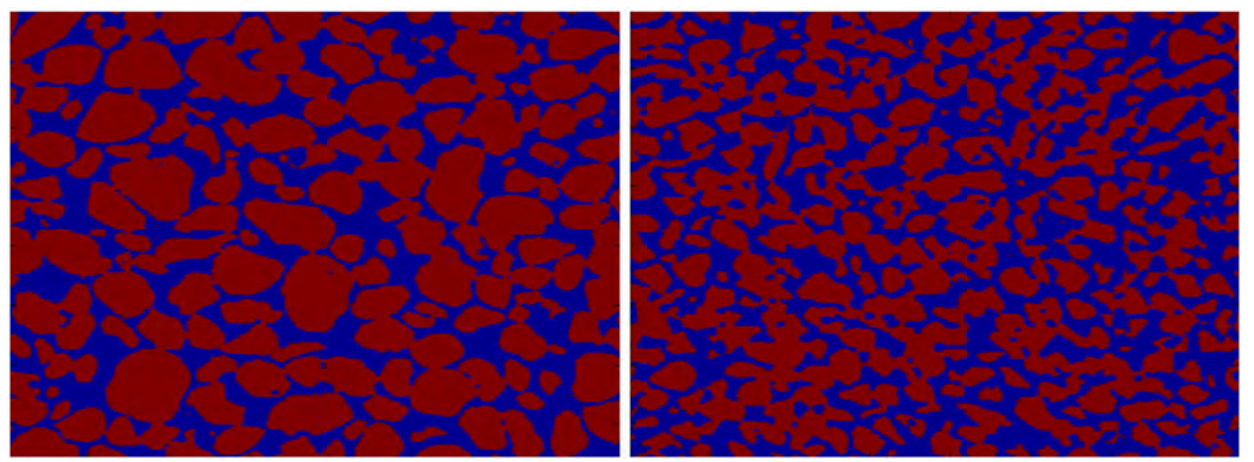

Fig. 4. Cross section of silica sand (S1) (left) and mixed sand (M1) (right). Red color depicts sand particles and dark blue color represents the void space.

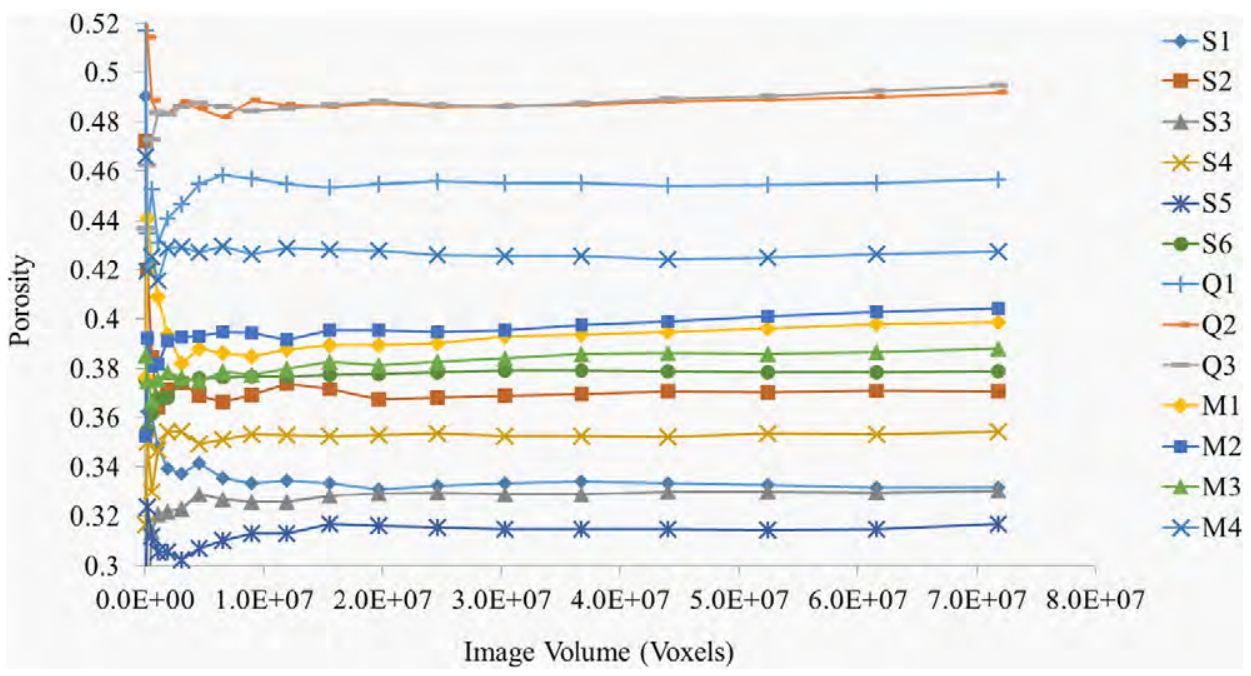

Fig. 5. Representative Elementary Volume (REV) analysis of the systems used for tortuosity computations. 


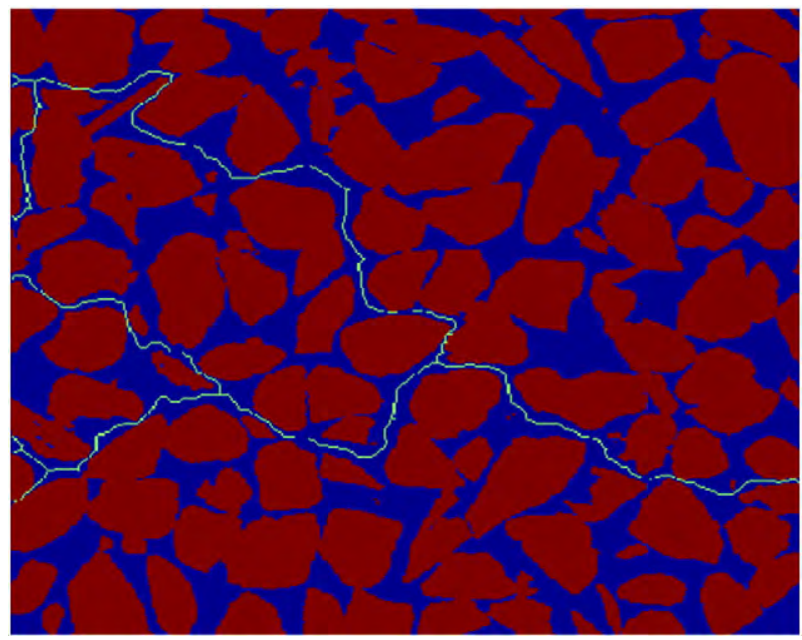

Fig. 6. All possible connected paths in a two-dimensional image of a silica sand (flow from left to right of the image). Red color depicts sand particles and dark blue color represents the void space.

520 voxels. All images of this size are considered representative elementary volume (REV) for porosity as shown in Fig. 5.

\subsection{Computation of tortuosity}

The algorithm was applied to compute tortuosity of natural sand systems given in Table 2. Computed values of tortuosity for all systems are given in Tables 4 and 5. Fig. 6 shows a cross-sectional image obtained from a 3D image to visualize the accuracy of the algorithm to find connected paths in the image. As can be seen from the image, all tortuous paths were accurately identified in the direction of flow (i.e., from left to right of the image). Similarly, Fig. 7 shows a cross-sectional image obtained from a 3D image to visualize the connected paths in the image when the direction of flow is from top to bottom of the image. Note that all computations are in 3D, however, Figs. 6 and 7 are used to better visualize the connected paths. Fig. 8 shows all connected paths in a 3D image when the direction of flow is in the vertical direction.

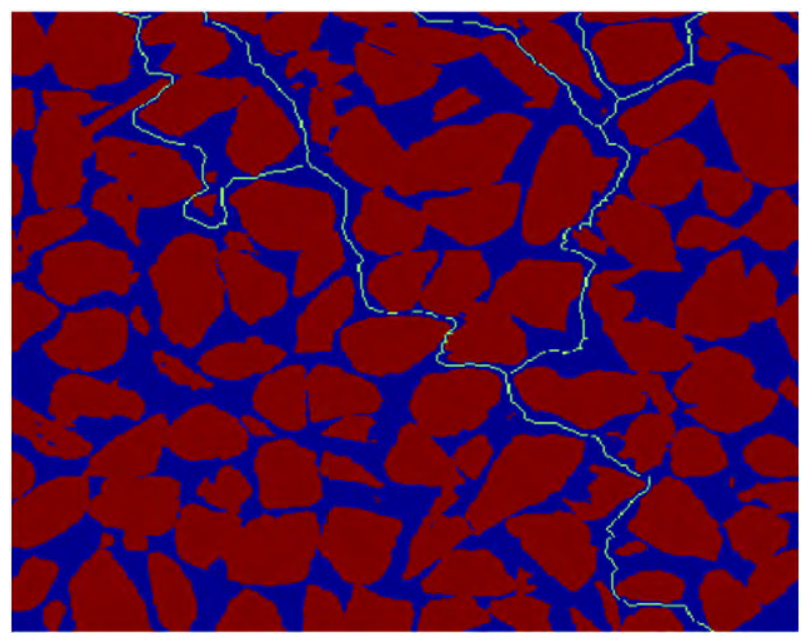

Fig. 7. All possible connected paths in a two-dimensional image of a silica sand (flow from top to bottom of the image). Red color depicts sand particles and dark blue color represents the void space.

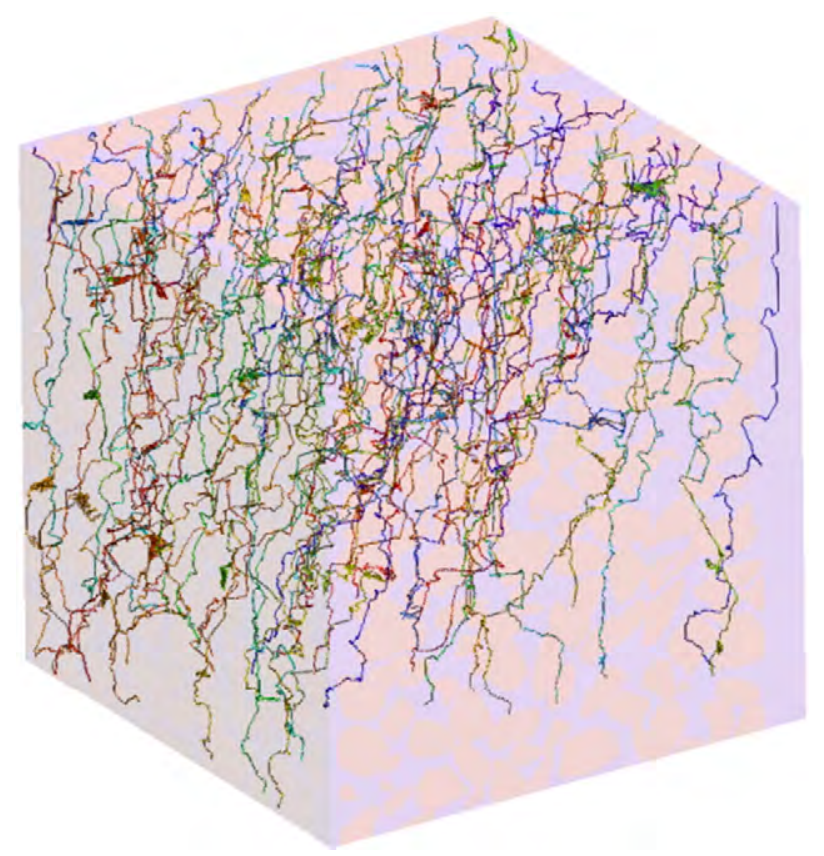

Fig. 8. All possible connected paths in a three-dimensional image of a silica sand (flow from top to bottom of the image).

Execution time required to compute tortuosity depends on the size of the image, complexity of the system analyzed and the machine used to perform the computations. Computational time needed to compute tortuosity was approximately $3 \mathrm{~min}$ for silica sands and 6 min for mixed sands using images with a size of $380 \times 380 \times 520$ voxels using a laptop with a $2.5 \mathrm{GHz}$ Intel Core i7 processer, with a memory of 16 GB RAM, $1600 \mathrm{MHz}$ running under Windows 8.1 environment.

\subsection{Comparison with available models}

Tortuosity values of sand systems given in Table 2 were computed by the developed code and compared with tortuosity values predicted by models reported in the literature. Table 3 summarizes models reported in the literature and used for comparison along with their conditions, derivation method and references. Values of tortuosity computed using the developed code and predicted using the models reported in the literature and relative differences are listed in Tables 4 and 5.

As shown in Table 3, Models 1, 2, 3 and 4 were obtained from systems comprised of spherical particles where they relate tortuosity to porosity. Tortuosity values predicated by these models were compared to values computed using the developed code for similar systems (i.e., S1, S2, S3 and S4) as shown in Table 4. Findings indicate that there is a good agreement between tortuosity values obtained using Tort3D and those obtained from model predictions of similar systems.

As shown in Table 3, Model 5 relates tortuosity to porosity whereas Model 6 related tortuosity to the median grain diameter. Both models were obtained from systems comprised of irregular particles. Tortuosity values predicated by Models 5 and 6 were compared to values computed using the developed code for similar systems (i.e., M1, M2, M3 and M4) as shown in Table 5. Findings indicate that there is a good agreement between tortuosity values obtained using Tort3D and those obtained from model predictions of similar systems.

While tortuosity is expressed as scalar value, one of the main advantages of the developed algorithm is that it provides a three-dimensional description of the tortuous paths in the void space which can be related to properties of pore space and the solid particles. This in turn can be useful to understand many transport mechanisms at the pore space that are influenced by tortuosity. 
Table 3

Tortuosity models available in the literature used to compare with tortuosity values obtained using the developed algorithm (i.e., Tort3D code).

\begin{tabular}{|c|c|c|c|c|}
\hline Model \# & Model & Condition & Derivation method & Reference \\
\hline 1 & $\tau=1-0.49 \ln \varepsilon$ & Bed of spheres & Experimental & [49] \\
\hline 2 & $\tau=\frac{1}{\varepsilon^{0.33}}$ & Granular packings & Analytical & {$[8,21]$} \\
\hline 3 & $\tau=1+0.64(1-\varepsilon)$ & Spherical particles & Numerical & [63] \\
\hline 4 & $\tau=\frac{\varepsilon}{1-(1-\varepsilon)^{\frac{2}{3}}}$ & Isotropic granular media & Analytical (based on a representative unit cell) & {$[20]$} \\
\hline 5 & $\tau=\sqrt{1+2(1-\varepsilon)}$ & Sandy marine sediments & Experimental (diffusion experiment) & {$[30]$} \\
\hline 6 & $\tau=0.19 d_{50}+1.45$ & Equation derived for 3D computed tomography images of Granusil and Accusand sands & Medial Axis algorithm in 3DMA-Rock package & [54] \\
\hline
\end{tabular}

$\varepsilon$ : porosity, $d_{50}$ : median grain diameter $(\mathrm{mm})$.

Table 4

Comparison between computed tortuosity of silica sand systems using Tort3D code with values obtained using Models 1, 2, 3 and 4 given in Table 3 .

\begin{tabular}{|c|c|c|c|c|c|c|c|c|c|}
\hline \multirow[t]{2}{*}{ Porous media } & \multirow{2}{*}{$\frac{\text { Tort3D Code }}{\tau}$} & \multicolumn{2}{|c|}{ Model 1} & \multicolumn{2}{|c|}{ Model 2} & \multicolumn{2}{|c|}{ Model 3} & \multicolumn{2}{|c|}{ Model 4} \\
\hline & & $\tau$ & Relative difference \% & $\tau$ & Relative difference $\%$ & $\tau$ & Relative difference $\%$ & $\tau$ & Relative difference \% \\
\hline S1 & 1.46 & 1.49 & 1.59 & 1.39 & 5.16 & 1.40 & 4.11 & 1.40 & 4.60 \\
\hline S2 & 1.42 & 1.54 & 8.94 & 1.44 & 1.78 & 1.43 & 0.83 & 1.41 & 0.62 \\
\hline S3 & 1.43 & 1.51 & 5.85 & 1.41 & 1.17 & 1.41 & 0.86 & 1.40 & 1.76 \\
\hline S4 & 1.51 & 1.56 & 3.66 & 1.46 & 3.11 & 1.44 & 4.59 & 1.41 & 6.19 \\
\hline S5 & 1.41 & 1.48 & 4.72 & 1.38 & 2.24 & 1.40 & 0.81 & 1.39 & 1.13 \\
\hline
\end{tabular}

\section{Conclusions}

In this paper, an algorithm was developed and implemented as a MATLAB code (i.e., Tort3D) to compute tortuosity from threedimensional images. The code reads a segmented image and finds all possible tortuous paths required to compute tortuosity. The code is user-friendly and easy to use where input parameters and user interaction are minimized. It has the option to select the direction of tortuosity computations along a given direction (i.e., $\mathrm{x}, \mathrm{y}$, or $\mathrm{z}$ ) and the connectivity of voxels (i.e., number of neighboring voxels/pixels while searching for connected paths). Moreover, it is computationally efficient, as it requires a relatively short time (few minutes) to identify all possible connected paths between two boundaries of large images. The main idea of the developed algorithm is that it conducts a guided search for connected paths in the void space of the image utilizing the medial surface of the void space. The advantage of this approach is that it limits the search along the medial surface, which in turn minimizes CPU time and memory requirements to find possible paths in the image. Once all connected paths are identified for a specific direction, the average of all connected paths in that direction is used to compute tortuosity.

Three-dimensional images of sand systems acquired using X-ray computed tomography were used to validate the code. Tortuosity was computed from three-dimensional images of nine different natural sand systems using the developed algorithm and compared with predicted values by models available in the literature. Findings indicate

Table 5

Comparison between computed tortuosity of mixed sand systems using Tort3D code with values obtained using Models 5 and 6 given in Table 3.

\begin{tabular}{|c|c|c|c|c|c|}
\hline \multirow{2}{*}{$\begin{array}{l}\text { Porous } \\
\text { media }\end{array}$} & \multirow{2}{*}{$\begin{array}{l}\text { Tort3D } \\
\text { code }\end{array}$} & \multicolumn{2}{|c|}{ Model 5} & \multicolumn{2}{|c|}{ Model 6} \\
\hline & & $\tau$ & $\begin{array}{l}\text { Relative difference } \\
\%\end{array}$ & $\tau$ & $\begin{array}{l}\text { Relative difference } \\
\%\end{array}$ \\
\hline M1 & 1.57 & 1.48 & 5.37 & 1.51 & 3.98 \\
\hline M2 & 1.56 & 1.48 & 5.31 & 1.50 & 4.25 \\
\hline M3 & 1.58 & 1.49 & 5.52 & 1.49 & 5.31 \\
\hline M4 & 1.53 & 1.46 & 4.57 & 1.49 & 3.12 \\
\hline
\end{tabular}

that the code can successfully compute tortuosity for any unconsolidated porous system irrespective of the shape (i.e., geometry) of particles.

\section{Acknowledgment}

Tomography imaging was performed at the GeoSoilEnviroCARS beamline (13-BM-D) at the Advanced Photon Source. GeoSoilEnviroCARS is supported by the National Science Foundation Earth Sciences (EAR0217473), Department of Energy Geosciences (DE-FG01-94ER14466), and the state of Illinois. Use of the APS was supported by the U.S. Department of Energy, Basic Energy Sciences, Office of Energy Research, under contract No. W-31-109-Eng-38.

\section{Appendix A. Supplementary data}

Supplementary data to this article can be found online at http://dx. doi.org/10.1016/j.powtec.2017.06.066.

\section{References}

[1] P.M. Adler, Porous Media: Geometry and Transports, Butterworth-Heinemann, Stoneham, 1992

[2] M.M. Ahmadi, S. Mohammadi, A.N. Hayati, Analytical derivation of tortuosity and permeability of monosized spheres: a volume averaging approach, Phys. Rev. E Stat. Nonlinear Soft Matter Phys. 83 (2) (2011) http://dx.doi.org/10.1103/PhysRevE.83.026312.

[3] B. Albers, K. Wilmanski, Anisotropic diffusion and propagation of sound waves in poroelastic media, Paper Presented at the Computational Methods for Coupled Problems in Science and Engineering V - A Conference Celebrating the 60th Birthday of Eugenio Onate, COUPLED PROBLEMS 2013, 2013.

[4] R.I. Al-Raoush, Experimental investigation of the influence of grain geometry on residual NAPL using synchrotron microtomography, J. Contam. Hydrol. 159 (2014) 1-10, http://dx.doi.org/10.1016/j.jconhyd.2014.01.008.

[5] N. Amiri, W. Yao, M. Heurich, P. Krzystek, A.K. Skidmore, Estimation of regeneration coverage in a temperate forest by 3D segmentation using airborne laser scanning data, Int. J. Appl. Earth Obs. Geoinf. 52 (2016) 252-262, http://dx.doi.org/10.1016/ j.jag.2016.06.022.

[6] G.P. Androutsopoulos, C.E. Salmas, Tomography of macro-meso-pore structure based on mercury porosimetry hysteresis loop scanning. Part I: MP hysteresis loop scanning along the overall penetration line, Chem. Eng. Commun. 181 (2000) 137-177.

[7] F. Bastardie, Y. Capowiez, J.R. De Dreuzy, D. Cluzeau, X-ray tomographic and hydraulic characterization of burrowing by three earthworm species in repacked soil cores, Appl. Soil Ecol. 24 (1) (2003) 3-16, http://dx.doi.org/10.1016/S0929-1393(03)00071-4.

[8] J. Bear, Dynamics of Fluids in Porous Media, American Elsevier Pub. Co., New York, 1972. 
[9] R. Cai, W.B. Lindquist, W. Um, K.W. Jones, Tomographic analysis of reactive flow induced pore structure changes in column experiments, Adv. Water Resour. 32 (9) (2009) 1396-1403, http://dx.doi.org/10.1016/j.advwatres.2009.06.006.

[10] M.D. Campiñez, I. Caraballo, M. Puchkov, M. Kuentz, Novel polyurethane matrix systems reveal a particular sustained release behavior studied by imaging and computational modeling, AAPS PharmSciTech (2016) 1-10, http://dx.doi.org/10. 1208/s12249-016-0613-0.

[11] D.S. Cheon, M. Takahashi, E.S. Park, Permeability change and geometrical information of void spaces in Berea sandstone and Otway sandstone, Geosystem Eng. (2016) 1-8, http://dx.doi.org/10.1080/12269328.2016.1209136.

[12] S.W. Coleman, J.C. Vassilicos, Transport properties of saturated and unsaturated porous fractal materials, Phys. Rev. Lett. 100 (3) (2008) http://dx.doi.org/10.1103/ PhysRevLett.100.035504

[13] N.D. Cornea, D. Silver, P. Min, Curve-skeleton properties, applications, and algorithms, IEEE Trans. Vis. Comput. Graph. 13 (3) (2007) 530-548, http://dx.doi.org/ 10.1109/TVCG.2007.1002.

[14] B.R. Corrochano, J.R. Melrose, A.C. Bentley, P.J. Fryer, S. Bakalis, A new methodology to estimate the steady-state permeability of roast and ground coffee in packed beds, J. Food Eng. 150 (2014) 106-116, http://dx.doi.org/10.1016/j.jfoodeng.2014.11.006,

[15] R.A. Dawe, Enhancing oil recovery, J. Chem. Technol. Biotechnol. 51 (3) (1991) 361-393, http://dx.doi.org/10.1002/jctb.280510308.

[16] G. Desmet, M. Callewaert, H. Ottevaere, W. De Malsche, Merging open-tubular and packed bed liquid chromatography, Anal. Chem. 87 (14) (2015) 7382-7388, http://dx.doi.org/10.1021/acs.analchem.5b01579.

[17] R. Dechter, J. Pearl, Generalized best-first search strategies and the optimality of $A^{*}$, J. ACM 32 (3) (1985) 505-536, http://dx.doi.org/10.1145/3828.3830.

[18] E. Dijkstra, A Note on Two Problems in Connexion with Graphs, 1959

[19] L. Ding, H. Li, Parallel processing for accelerated Mean Shift algorithm based on TBB, Paper Presented at the International Geoscience and Remote Sensing Symposium (IGARSS), 2016.

[20] J.P. Du Plessis, J.H. Masliyah, Flow through isotropic granular porous media, Transp. Porous Media 6 (3) (1991) 207-221, http://dx.doi.org/10.1007/BF00208950

[21] F.A.L. Dullien, Single phase flow through porous media and pore structure, Chem. Eng. J. 10 (1) (1975) 1-34, http://dx.doi.org/10.1016/0300-9467(75)88013-0.

[22] A. Ellahyani, M.E. Ansari, Mean shift and log-polar transform for road sign detection, Multimedia Tools and Applications 2016, pp. 1-19, http://dx.doi.org/10.1007/ s11042-016-4207-3.

[23] H.I. Essaid, B.A. Bekins, I.M. Cozzarelli, Organic contaminant transport and fate in the subsurface: evolution of knowledge and understanding, Water Resour. Res. 51 (7) (2015) 4861-4902, http://dx.doi.org/10.1002/2015WR017121.

[24] X. Gao, J.C. Diniz da Costa, S.K. Bhatia, Understanding the diffusional tortuosity of porous materials: an effective medium theory perspective, Chem. Eng. Sci. 110 (2014) 55-71, http://dx.doi.org/10.1016/j.ces.2013.09.050.

[25] B. Ghanbarian, A.G. Hunt, R.P. Ewing, M. Sahimi, Tortuosity in porous media: a critical review, Soil Sci. Soc. Am. J. 77 (5) (2013) 1461-1477, http://dx.doi.org/10.2136/ sssaj2012.0435.

[26] R.M. Gowda, G.M. Lingaraju, Texture-based watershed 3D medical image segmentation based on fuzzy region growing approach, Advances in Intelligent Systems and Computing, Vol. 509, 2017, pp. 233-243.

[27] P. Grathwohl, Diffusion in Natural Porous Media: Contaminant Transport, Sorption/ Desorption and Dissolution Kinetics, Kluwer Academic Publishing, Boston, 1998.

[28] M.F. Hernández-López, J. Gironás, I. Braud, F. Suárez, J.F. Muñoz, Assessment of evaporation and water fluxes in a column of dry saline soil subject to different water table levels, Hydrol. Process. 28 (10) (2014) 3655-3669, http://dx.doi.org/10.1002/hyp.9912.

[29] L.B. Hu, C. Savidge, D.M. Rizzo, N. Hayden, J.W. Hagadorn, M. Dewoolkar, Commonly used porous building materials: geomorphic pore structure and fluid transport J. Mater. Civ. Eng. 25 (12) (2013) 1803-1812, http://dx.doi.org/10.1061/ (ASCE)MT.1943-5533.0000706

[30] N. Iversen, B.B. Jørgensen, Diffusion coefficients of sulfate and methane in marine sediments: influence of porosity, Geochim. Cosmochim. Acta 57 (3) (1993) 571-578, http://dx.doi.org/10.1016/0016-7037(93)90368-7.

[31] H. Jia, S. Ding, M. Du, Y. Xue, Approximate normalized cuts without Eigendecomposition, Inf. Sci. 374 (2016) 135-150, http://dx.doi.org/10.1016/j.ins.2016 09.032

[32] V. Joekar-Niasar, F. Doster, R.T. Armstrong, D. Wildenschild, M.A. Celia, Trapping and hysteresis in two-phase flow in porous media: a pore-network study, Water Resour. Res. 49 (7) (2013) 4244-4256, http://dx.doi.org/10.1002/wrcr.20313.

[33] P.S. Jørgensen, K.V. Hansen, R. Larsen, J.R. Bowen, Geometrical characterization of interconnected phase networks in three dimensions, J. Microsc. 244 (1) (2011) 45-58, http://dx.doi.org/10.1111/j.1365-2818.2011.03504.x.

[34] J. Jung, M. Hamachi, Y. Obara, I. Tanikura, S. Watanabe, Analysis of damage in specimen under cyclic uniaxial loading test by X-ray CT method, Paper Presented at the ISRM International Symposium - 8th Asian Rock Mechanics Symposium, ARMS 2014, 2014

[35] V. Karanikola, A.F. Corral, H. Jiang, A.E. Sáez, W.P. Ela, R.G. Arnold, Effects of membrane structure and operational variables on membrane distillation performance, J. Membr. Sci. 524 (2017) 87-96, http://dx.doi.org/10.1016/j.memsci.2016.11.038.

[36] A.S. Kavitha, P. Shivakumara, G.H. Kumar, T. Lu, A new watershed model based system for character segmentation in degraded text lines, AEU Int. J. Electron. Commun. 71 (2017) 45-52, http://dx.doi.org/10.1016/j.aeue.2016.11.007.

[37] I.E. Kaya, A.Ç. Pehlivanl,, E.G. Sekizkardeş, T. Ibrikci, PCA based clustering for brain tumor segmentation of T1w MRI images, Comput. Methods Prog. Biomed. 140 (2017) 19-28, http://dx.doi.org/10.1016/j.cmpb.2016.11.011

[38] L.M. Keller, A. Hilger, I. Manke, Impact of sand content on solute diffusion in Opalinus Clay, Appl. Clay Sci. 112-113 (2015) 134-142, http://dx.doi.org/10.1016/ j.clay.2015.04.009.

[39] D. Khattab, H.M. Ebeid, A.S. Hussein, M.F. Tolba, 3D mesh segmentation based on unsupervised clustering, Advances in Intelligent Systems and Computing, Vol. 533, 2017, pp. 598-607.

[40] G.R. Klinzing, A. Zavaliangos, A simplified model of moisture transport in hydrophilic porous media with applications to pharmaceutical tablets, J. Pharm. Sci. 105 (8) (2016) 2410-2418, http://dx.doi.org/10.1016/j.xphs.2016.05.030.
41] P.Y. Lanfrey, Z.V. Kuzeljevic, M.P. Dudukovic, Tortuosity model for fixed beds randomly packed with identical particles, Chem. Eng. Sci. 65 (5) (2010) 1891-1896, http://dx.doi.org/10.1016/j.ces.2009.11.011.

[42] A. Li, S. Payandeh, An overview of path tortuosity measures for tracking and monitoring, Paper Presented at the 7th IEEE Annual Information Technology, Electronics and Mobile Communication Conference, IEEE IEMCON 2016, 2016.

[43] J.H. Li, B.M. Yu, Tortuosity of flow paths through a Sierpinski carpet, Chin. Phys. Lett. 28 (3) (2011) http://dx.doi.org/10.1088/0256-307X/28/3/034701.

[44] W.B. Lindquist, S.M. Lee, D.A. Coker, K.W. Jones, P. Spanne, Medial axis analysis of void structure in three-dimensional tomographic images of porous media, J. Geophys. Res. B: Solid Earth 101 (4) (1996) 8297-8310.

[45] S. Lu, H. Huang, P. Liang, G. Chen, L. Xiao, Hepatic vessel segmentation using variational level set combined with non-local robust statistics, Magn. Reson. Imaging 36 (2017) 180-186, http://dx.doi.org/10.1016/j.mri.2016.10.021.

[46] L. Luo, H. Lin, P. Halleck, Quantifying soil structure and preferential flow in intact soil using X-ray computed tomography, Soil Sci. Soc. Am. J. 72 (4) (2008) 1058-1069, http://dx.doi.org/10.2136/sssaj2007.0179.

[47] F. Malmberg, C.L. Luengo Hendriks, R. Strand, Exact evaluation of targeted stochastic watershed cuts, Discret. Appl. Math. 216 (2017) 449-460, http://dx.doi.org/10 1016/j.dam.2016.01.006

[48] M. Matyka, A. Khalili, Z. Koza, Tortuosity-porosity relation in porous media flow, Phys. Rev. E Stat. Nonlinear Soft Matter Phys. 78 (2) (2008) http://dx.doi.org/10 1103/PhysRevE.78.026306.

[49] E. Mauret, M. Renaud, Transport phenomena in multi-particle systems-I. Limits of applicability of capillary model in high voidage beds-application to fixed beds of fibers and fluidized beds of spheres, Chem. Eng. Sci. 52 (11) (1997) 1807-1817, http://dx.doi.org/10.1016/S0009-2509(96)00499-X.

[50] J.M. Montes, F.G. Cuevas, J. Cintas, Electrical and thermal tortuosity in powder compacts, Granul. Matter 9 (6) (2007) 401-406, http://dx.doi.org/10.1007/s10035-0070061-3.

[51] H. Mori, L. Trevisan, T.H. Illangasekare, Evaluation of relative permeability functions as inputs to multiphase flow models simulating supercritical $\mathrm{CO}_{2}$ behavior in deep geologic formations, Int. J. Greenhouse Gas Control 41 (2015) 328-335, http://dx doi.org/10.1016/j.ijggc.2015.05.023.

[52] R.H. Morin, D.R. LeBlanc, B.M. Troutman, The influence of topology on hydraulic conductivity in a sand-and-gravel aquifer, Ground Water 48 (2) (2010) 181-190 http://dx.doi.org/10.1111/j.1745-6584.2009.00646x.

[53] A. Mostafa, M. Houseni, N. Allam, A.E. Hassanien, H. Hefny, P.W. Tsai, Antlion optimization based segmentation for MRI liver images, Advances in Intelligent Systems and Computing, Vol. 536, 2017, pp. 265-272.

[54] M. Naveed, S. Hamamoto, K. Kawamoto, T. Sakaki, M. Takahashi, T. Komatsu, L.W. De Jonge, Correlating gas transport parameters and X-ray computed tomography measurements in porous media, Soil Sci. 178 (2) (2013) 60-68, http://dx.doi.org/10 1097/SS.0b013e318288784c.

[55] S. Neethirajan, D.S. Jayas, N.D.G. White, H. Zhang, Investigation of 3D geometry of bulk wheat and pea pores using X-ray computed tomography images, Comput. Electron. Agric. 63 (2) (2008) 104-111, http://dx.doi.org/10.1016/j.compag.2008.01.019.

[56] N.F. Ngom, P. Garnier, O. Monga, S. Peth, Extraction of three-dimensional soil pore space from microtomography images using a geometrical approach, Geoderma 163 (1-2) (2011) 127-134, http://dx.doi.org/10.1016/j.geoderma.2011.04.013.

[57] Y. Obara, I. Tanikura, J. Jung, R. Shintani, S. Watanabe, Evaluation of micro-damage of concrete specimens under cyclic uniaxial loading by X-ray CT method, J. Adv. Concr. Technol. 14 (8) (2016) 433-443, http://dx.doi.org/10.3151/jact.14.433.

[58] S. Pardo-Alonso, J. Vicente, E. Solórzano, M.Á. Rodriguez-Perez, D. Lehmhus Geometrical tortuosity 3D calculations in infiltrated aluminium cellula materials, Prog. Mater. Sci. 4 (2014) 145-150, http://dx.doi.org/10.1016/j. mspro.2014.07.553.

[59] S. Peng, F. Marone, S. Dultz, Resolution effect in X-ray microcomputed tomography imaging and small pore's contribution to permeability for a Berea sandstone, J. Hydrol. 510 (2014) 403-411, http://dx.doi.org/10.1016/j.jhydrol.2013.12.028.

[60] J. Perret, S.O. Prasher, A. Kantzas, C. Langford, A two-domain approach using CAT scanning to model solute transport in soil, J. Environ. Qual. 29 (3) (2000) 995-1010.

[61] K.Z. Phyo, M.M. Sein, Optimal route finding for weak infrastructure road network Advances in Intelligent Systems and Computing, Vol. 536, 2017, pp. 230-237.

[62] A. Pierret, Y. Capowiez, L. Belzunces, C.J. Moran, 3D reconstruction and quantification of macropores using X-ray computed tomography and image analysis, Geoderma 106 (3-4) (2002) 247-271, http://dx.doi.org/10.1016/S0016-7061(01)00127-6.

63] L. Pisani, Simple expression for the tortuosity of porous media, Transp. Porous Media 88 (2) (2011) 193-203, http://dx.doi.org/10.1007/s11242-011-9734-9.

[64] M. Prodanović, W.B. Lindquist, R.S. Seright, Porous structure and fluid partitioning in polyethylene cores from 3D X-ray microtomographic imaging, J. Colloid Interface Sci. 298 (1) (2006) 282-297, http://dx.doi.org/10.1016/j.jcis.2005.11.053.

[65] M.A.B. Promentilla, T. Sugiyama, T. Hitomi, N. Takeda, Quantification of tortuosity in hardened cement pastes using synchrotron-based X-ray computed microtomography, Cem. Concr. Res. 39 (6) (2009) 548-557, http://dx.doi.org/10.1016/j.cemconres.2009 03.005 .

66] M.A.B. Promentilla, S.M. Cortez R.A.D.C. Papel, B.M. Tablada, T. Sugiyama, Evaluation of microstructure and transport properties of deteriorated cementitious materials from their X-ray computed tomography (CT) images, Materials 9 (5) (2016), http://dx.doi. org/10.3390/ma9050388.

[67] Z. Ranachowski, D. Jóźwiak-Niedźwiedzka, P. Ranachowski, M. Dąbrowski, S. Kudela Jr. T. Dvorak, The determination of diffusive tortuosity in concrete specimens using X-ray microtomography, Arch. Metall. Mater. 60 (2A) (2015) 1115-1119, http://dx. doi.org/10.1515/amm-2015-0140.

[68] A.S. Rathore, E. Wen, C. Horváth, Electrosmotic mobility and conductivity in columns for capillary electrochromatography, Anal. Chem. 71 (14) (1999) 2633-2641, http://dx.doi.org/10.1021/ac9900735.

[69] A.H. Reed, K.E. Thompson, K.B. Briggs, C.S. Willson, Physical pore properties and grain interactions of SAX04 sands, IEEE J. Ocean. Eng. 35 (3) (2010) 488-501, http://dx.doi.org/10.1109/JOE.2010.2040656. 
[70] D. Rotger, M. Rosales, J. Garcia, O. Pujol, J. Mauri, P. Radeva, Active vessel: a new multimedia workstation for intravascular ultrasound and angiography fusion, Paper Presented at the Computers in Cardiology, 2003.

[71] P.K. Saha, G. Borgefors, G. Sanniti di Baja, A survey on skeletonization algorithms and their applications, Pattern Recogn. Lett. (2015) http://dx.doi.org/10.1016/j.patrec. 2015.04.006.

[72] R. Saleh, N.C. Ali, Y. Abuahmad, N. Otaibi, A. Osman, M. Farid, ... I. El-Fouly, Optimizing Saudi Aramco reentry drilling operations with the first worldwide combined high dogleg RSS and underreaming drilling system, Paper Presented at the Society of Petroleum Engineers - SPE Saudi Arabia Section Technical Symposium and Exhibition, 2014

[73] C.E. Salmas, G.P. Androutsopoulos, A novel pore structure tortuosity concept based on nitrogen sorption hysteresis data, Ind. Eng. Chem. Res. 40 (2) (2001) 721-730.

[74] G.R. Samuel, K. Bharucha, Y. Luo, Tortuosity factors for highly tortuous wells: a practical approach, Paper Presented at the SPE/IADC Drilling Conference, Proceedings, 2005.

[75] N.O. Shanti, Microstructurally Tailored Ceramics for Advanced Energy Applications by Thermoreversible Gelcasting, Northwestern University, 2010.

76] N.O. Shanti, V.W.L. Chan, S.R. Stock, F. De Carlo, K. Thornton, K.T. Faber, X-ray microcomputed tomography and tortuosity calculations of percolating pore networks, Acta Mater. 71 (2014) 126-135, http://dx.doi.org/10.1016/j.actamat.2014.03.003.

[77] S. Shi, Y. Wang, L. Wang, Y. Jin, T. Wang, W. Li, Effect of shear action on enhanced oi recovery of spontaneous emulsification flooding, Oilfield Chem. 33 (2) (2016) 295-299, http://dx.doi.org/10.19346/j.cnki.1000-4092.2016.06.022.

[78] K. Soukup, V. Hejtmánek, P. Čapek, K. Stanczyk, O. Šolcová, Modeling of contaminant migration through porous media after underground coal gasification in shallow coal seam, Fuel Process. Technol. 140 (2015) 188-197, http://dx.doi.org/10.1016/j. fuproc.2015.08.033.

[79] Z. Sun, X. Tang, G. Cheng, Numerical simulation for tortuosity of porous media, Microporous Mesoporous Mater. 173 (2013) 37-42, http://dx.doi.org/10.1016/j. micromeso.2013.01.035.

[80] H. Takahashi, Y. Seida, M. Yui, 3D X-ray CT and diffusion measurements to assess tortuosity and constrictivity in a sedimentary rock, Open-Access J. Basic Princ. Diffus. Theory Exp. Appl. 11 (89) (2009) 1-11.

[81] M. Takahashi, N. Takada, M. Sato, W. Lin, Three dimensional pore geometry and fluid flow of Kimachi sandstone under different stress condition: suggestion to conservation of tuffacious world cultural heritage, Engineering Geology for Society and Territory - Volume 8: Preservation of Cultural Heritage 2015, pp. 135-138.

[82] C.F. Tsai, Y.H. Hu, W.C. Lin, The effect of region segmentation on object categorization, Paper Presented at the ICSPCC 2016 - IEEE International Conference on Signal Processing, Communications and Computing, Conference Proceedings, 2016.

[83] R.P. Udawatta, C. Gantzer, S.H. Anderson, A.M. Rossi, R.C. Graham, R.A. Ketcham, Analysis of three-dimensional geometrical pore parameters from rock weathering, Soil Sci. 177 (8) (2012) 506-516, http://dx.doi.org/10.1097/SS.0b013e31825f20c6.

[84] C.J. Van Duijn, X. Cao, I.S. Pop, Two-phase flow in porous media: dynamic capillarity and heterogeneous media, Transp. Porous Media 114 (2) (2016) 283-308, http://dx. doi.org/10.1007/s11242-015-0547-0.

[85] R.W. Vervoort, S.R. Cattle, Linking hydraulic conductivity and tortuosity parameters to pore space geometry and pore-size distribution, J. Hydrol. 272 (1-4) (2003) 36-49, http://dx.doi.org/10.1016/S0022-1694(02)00253-6.

[86] C. Wang, Y. Tang, X. Zou, W. SiTu, W. Feng, A robust fruit image segmentation algorithm against varying illumination for vision system of fruit harvesting robot, Optik 131 (2017) 626-631, http://dx.doi.org/10.1016/j.ijleo.2016.11.177.

[87] S. Wherity, T. Sidley, M. Cowling, A. Ismayilov, J. Noe-Nygaard, Observation and monitoring well: in situ window to assess recovery efficiency, Paper Presented at the Proceedings - SPE Annual Technical Conference and Exhibition, 2014.

[88] B.M. Yu, J.H. Li, A geometry model for tortuosity of flow path in porous media, Chin. Phys. Lett. 21 (8) (2004) 1569-1571, http://dx.doi.org/10.1088/0256-307X/21/8/ 044.

[89] Y. Zhou, D. Zheng, P. Ashok, E. Van Oort, Improved wellbore quality using a novel real-time tortuosity index, Paper Presented at the SPE/IADC Drilling Conference, Proceedings, 2016.

[90] T.G. Zieliński, Inverse identification and microscopic estimation of parameters for models of sound absorption in porous ceramics, Paper Presented at the International Conference on Noise and Vibration Engineering 2012, ISMA 2012, Including USD 2012: International Conference on Uncertainty in Structure Dynamics, 2012.

[91] Y. Feng, B. Yu, M. Zou, P. Xu, A generalized model for the effective thermal conductivity of unsaturated porous media Based on self-similarity, J. Porous. Media 10 (6) (2007) 551-567, http://dx.doi.org/10.1615/JPorMedia.v10.i6.30. 